\title{
Integrating GIS and expert judgment in a multi-criteria analysis to map and develop a habitat suitability index: a case study of large mammals on the Malayan Peninsula
}

\begin{abstract}
Many habitat patches in tropical landscapes have become less suitable for wildlife due to an increase in anthropogenic disturbances. An index of habitat suitability based on the ecological factors that collectively determine the suitability of an organism's habitat is important for conservation planning. However, a widely accepted and comprehensive multicriteria habitat suitability index for umbrella species is still lacking, particularly in areas where information related to the biology and ecology of the species of interest is not available. Therefore we develop preliminary habitat maps and measure the degree of habitat suitability for large mammals, focusing on four umbrella species in the State of Selangor, Peninsular Malaysia: Panthera tigris jacksoni (Malayan tiger), Tapirus indicus (Malayan tapir), Helarctos malayanus malayanus (Malayan sun bear), and Rusa unicolor cambojensis (sambar deer). The former two are endangered and the latter two are vulnerable according to the IUCN Red List. The suitability of habitat patches for each species was measured across the entire study area as well as in nine wildlife protected areas by integrating GIS data and expert opinion. Expert opinions were used as the source of information regarding the stresses faced by the species because there was insufficient information available from ground surveys. We developed an index and maps of habitat suitability for each species, which were then integrated to represent a combined index (ranging from 0 to 27) and spatially explicit maps of the area's habitat suitability for large mammals. The average large mammal habitat suitability index value of the State of Selangor (9) indicates that many habitat patches have become unsuitable for such species. Of the nine wildlife protected areas, Fraser's Hill (22), Sungai Dusun (22), and Bukit Kutu (21) are very suitable; Klang Gate (20) and Templers Park (17) are suitable; and the remaining four are unsuitable for large mammals. We assume that this preliminary habitat suitability index and mapping are useful for conservation planning of wildlife habitats at both landscape and regional scales, as well as providing an initial foundation for revision by future research with significant new information.
\end{abstract}

Keyword: Conservation planning; Expert judgment; Landscape and regional planning; Multi-criteria decision making (MCDM); Habitat suitability mapping; Wildlife conservation 